удК 331.5

\author{
В. Г. Былков \\ Байкальский государственный университет, \\ г. Иркутск, Российская Федерация
}

\title{
ПРЕДЛОЖЕНИЕ НА РЫНКЕ ТРУДА: МЕТОДОЛОГИЯ, ПРИРОДА ФОРМИРОВАНИЯ
}

\begin{abstract}
АНнОТАЦИя. В современных условиях развития рынка труда особое значение приобретают вопросы оптимального соотношения спроса и предложения. Традиционно в теории и практике изучения процессов формирования предложения труда выделялись факторы, связанные с уровнем оплаты труда. Дальнейшее развитие теории рынка труда предполагает изучение и раскрытие природы и содержания предложения. Выявлен вероятностный характер формирования предложения на рынке труда. Это обусловлено тем, что методологической дефиницией предложения выступают мотивы и желание получить рабочее место, работу. Выделены факторы, формирующие предложение индивидуальной рабочей силы, которые носят мотивационно-корректирующий характер. Исследуя влияние внешних (объективных) и внутренних (субъективных) факторов, автором определены условия и предпосылки формирования предложения, выявлены этапы трансформации. Подчеркивается, что в современных условиях предлагаемые подходы развития рынка труда приобретают ключевые вопросы согласования спроса и предложения на рынке труда в зависимости от природы и процессов формирования потребностей в трудовой деятельности.

кЛючЕВЫЕ словА. Рынок труда; предложение труда; поиск рабочего места; условия; предпосылки и факторы формирования индивидуального предложения; стадии процесса формирования предложения; мотивационно-корректирующее предложение; уровни формирования предложения.

ИНФОРМАЦИЯ О СТАТЬЕ. Дата поступления 22 июня 2017 г.; дата принятия к печати 19 декабря 2017 г.; дата онлайн-размещения 29 декабря 2017 г.
\end{abstract}

\section{G. Bylkov \\ Baikal State University, Irkutsk, Russian Federation}

\section{SUPPLY ON THE LABOR MARKET: METHODOLOGY, NATURE OF FORMATIONS}

ABSTRACT. Issues of the optimal correlation of supply and demand take on particular importance in the current context of the labor market development. Traditionally, in the theory and practice of studying the processes of labor supply formation, factors related to the compensation rate have been revealed. Further development of the labor market theory involves study and disclosure of the nature and content of the supply. The article reveals the probabilistic nature of the supply formation on the labor market. This is due to the fact that the methodological definition of the supply is a motivation and desire to get a job or work. The article identifies the factors forming the supply of individual labor, which have a motivational and corrective nature. While investigating the influence of external (objective) and internal (subjective) factors, the author determines the conditions and prerequisites for the supply formation and identifies the stages of transformation. It is emphasized that in the current context the proposed approaches to the labor market development take on the key issues of supply and demand coordination on the labor market, depending on the nature and formation processes of a need for labor activity.

KEYWORDS. Labor market; labor supply; search workplace; conditions; prerequisites and factors of forming individual supply; stages of proposal formation process; motivational and corrective proposal; levels of supply formation.

\section{Baikal Research Journal}


ARTICLE INFO. Received June 22, 2017; accepted December 19, 2017; available online December 29, 2017.

Как правило предложение на рынке труда означает количество услуг труда, которое может быть предложено на рынке труда по определенной цене в определенное время [1, с. $60 ; 2$, с. 87$]$.

Подчеркивая характерные особенности субъектов предложения, многие ученые-экономисты отмечают, что предложение представляет собой предложение наемным работником принадлежащей ему и неотделимой от него способности к труду, выступающей в качестве товара на рынке труда, покупателю данного специфического товара-работодателю за определенную плату, на определенный временной период [3, с. 114]. Тем самым, утверждается, что работник, обладающий уникальным товаром «рабочая сила», предлагает его собственнику средств производства. При этом часто не уточняется, что носителем товара могут быть не только «работники», но и те, кто входит состав рабочей силы. Несомненно, справедливо лишь единственное утверждение, что процесс формирования предложения на рынке труда происходит на индивидуальном уровне.

Поэтому, цели, потребности, социально-экономические интересы и качественные характеристики лиц, входящих в рабочую силу имея весьма различные параметры, представляют различные аспекты предложения. В зависимости от изменения качественных и количественных параметров субъектов предложения можно судить о тенденциях и условиях волатильности емкости предложения. К примеру, отмечается, что образовательные характеристики рабочей силы могут являться основой согласования предложения и спроса на рынке труда [4].

Поэтому важнейшей методической проблемой в теории рынка труда является определение факторов, которые воздействуют на величину емкости предложения на локальном, региональном и национальных рынках труда. Традиционно классической экономической теорией определяется, что предложение труда зависит, прежде всего, от уровня его оплаты [5]. В современной экономике труда, как правило, взаимосвязь между предложением труда и его ценой - заработной платой - выражается законом предложения труда. Совершенно справедливо утверждение, что на рынке труда совершенной конкуренции величина предложения труда находится в прямой зависимости от его цены [6, с. 114].

Это связано с тем, что предложение труда предопределяется потребностями людей трудоспособного возраста в обычном воспроизводстве своих оно, также как и спрос, зависит от величины заработной платы [3].

Теоретически предполагается, что для определенного вида труда при данной заработной плате, предложение складывается, как сумма объемов предложения всех работников. Причем, зависимость между уровнем заработной платы и величиной предложения труда представляется в виде изменения различных вариантов социально-экономических параметров.

Между тем, предложение на рынке труда не всегда сопряжено с воздействием цены труда, размером заработной платы на изменение его масштабов. Действительно, это важнейший, но не всегда главный аргумент формирования предпосылок превращения предложения труда. Иногда, подчеркивают зависимость предложения от ставок и изменения налогов на заработную плату [7].

В некоторых случаях, волатильность объемов предложения сопряжена с физическими и интеллектуальными способностями обладающих производительными работниками, с доступностью к различным источникам формирования доходов в том числе кроме зарплаты. Это утверждение обусловлено тем, что среди различных вариантов материального обеспечения индивида могут быть пенсии, пособия,

\section{Baikal Research Journal}

электронный научный журнал Байкальского государственного университета 
субсидии, проценты с вложенного капитала, дивиденды и любые другие доходы, для получения которых нет необходимости непосредственно трудиться [8, с. 96]. Поэтому можно считать, что предложение основано на личном выборе между работой и досугом, соизмерении альтернативной стоимости предлагаемого работодателем труда. В конечном счете, в основе изучения формирования предложения лежат методологические принципы определения взаимосвязи и выбора между временем досуга и труда, основанного на соизмерении возможного получения дохода от трудовой деятельности.

Традиционно эффект дохода ориентируется на том, что с увеличением совокупного дохода при стабильной ставке оплаты (определяющей оплату в единицу времени) снижается желательная продолжительность рабочего времени. Соответственно, если, например, «целью» агента является поддержание совокупного дохода постоянным, то увеличение ставки оплаты в рамках эффекта дохода приведет к сокращению желательной продолжительности рабочего времени, и наоборот - для поддержания дохода постоянным при сокращении ставки оплаты желательная продолжительность рабочего времени будет возрастать.

В свою очередь, эффект замещения состоит в том, что увеличение ставки оплаты приводит к увеличению желательной продолжительности рабочего времени, то есть альтернативные издержки одного часа досуга возрастают и агент предпочитает отработать большее количество часов. В терминах экономической теории это означает, что решение выхода на рынок труда будет зависеть от того, как соотносится предлагаемый и резервный уровни заработной платы для данного индивида.

Таким образом, в случае если доминирует әффект дохода, то агент реагирует на повышение ставки заработной платы сокращением предложения труда. С другой стороны, если преобладает эффект замещения, предложение труда увеличивается. В современной теории экономики труда получаемая кривая получила название "кривой обратного изгиба» [6]. Часто утверждается, что, зная выявленные зависимости между доходом и свободным временем можно смоделировать стратегию индивидуального поведения на рынке труда. Достаточно подробно процесс формирования индивидуального предложения представлен в книге «Индивидуальные стратегии предложения труда: теория и практика» [9], вышедшей в начале 2000-х. Авторам были определены принципы, которые формируют индивидуальные стратегии предложения труда.

Подчеркивается, что при заданной ставке оплаты, выбирая желательную продолжительность рабочего времени, каждый агент руководствуется теми или иными индивидуальными принципами, отражающими его предпочтения на рынке труда. Устанавливая и учитывая совокупность конкретных принципов можно условно фиксировать стратегии индивидуального поведения на рынке труда. $\mathbf{K}$ примеру, только для четырех вариантов описания индивидуальных предпочтений возможны шестнадцать их попарных комбинаций. Как подчеркивается, такое упрощающее предположение исключает из рассмотрения задачи принятия агентом решений о найме, увольнении, смене и поиске работы и т. д. [6].

Действительно, вариантов индивидуальных стратегий, основанных на конкретных принципах выбора достаточно большое количество. На самом деле при формировании предложения на рынке труда, вариантов выбора предпочтений гораздо больше. Очевидно это связано с тем, что при выборе предпочтений на рынке труда на индивидуальном уровне в пользу занятия трудовой деятельности влияет достаточно большое количество условий и предпосылок. Несомненно, стоит учитывать, как объективные, так и субъективные условия, воздействующие на принятие решений о предложении рабочей силы на рынке труда. $K$ тому же, фор-

\section{Baikal Research Journal}

электронный научный журнал Байкальского государственного университета 
мирование предложения на рынке труда должно соизмеряться со сложившимся спросом на труд [10, с. 417].

Это связано с тем, что в реальной экономике, предложение рабочей силы формируется и изменяется под действием не только целого комплекса объективных, но и субъективных факторов [11, с. 28-36]. В конечном счете следует выделить методологические постулаты, которые теоретически раскрывают сущность формирования индивидуального предложения на рынке труда.

Во-первых, прежде всего предложение формируется на индивидуальном уровне или в сфере отдельного домохозяйства [12]. Это связано с тем, что решение индивида (агента) о выходе на рынок труда или смены места работы принимается именно на этом уровне.

Во-вторых, процесс формирования предложения имеет альтернативный, вариативный характер выбора между различными условиями жизнедеятельности человека (работой/досугом). Причем процесс формирования предложения труда носит сугубо личностный характер, поэтому имеет личностно-поведенческую регрессию.

В-третьих, формирование предложения осуществляется в условиях высокого уровня неопределенности, различного рода ограничителей и предполагает существенную степень вероятности наступления социально-поведенческого события- «выход на рынок труда». Принятие решений о выходе на рынок труда осуществляется под действием значительного количества мотивов, социально-экономических интересов принципов, которые формируют множество вариантов экономического поведения индивида.

Поэтому важно определить мотивационно-поведенческую стратегию индивидуального поведения индивида на рынке труда. Причем, существенным является выявление насколько рациональным является предложение на рынке труда, поскольку принятие решения о выходе на рынке труда не всегда рационально и зависит от множества объективных и субъективных условий и факторов.

Зная параметры и оценочные критерии, можно выявить траекторию предложения в тот или иной период времени. С одной стороны, учитывая вероятностный характер процесса формирования предложения сложно определить зависимость от целой совокупности условий, предположений и предпосылок данного процесса. Это связано с тем, что процесс формирования предложения носит весьма вероятностный характер, означающий высокую степень неопределенности выхода индивида на конкретный рынок труда. С другой стороны, появляется объективная необходимость учета условий и предпосылок, которые реально формируют предложение на рынке труда. В конечном счете, предложение на рынке труда представляет собой социально-психологическую дефиницию и ее изменение зависит от совокупности объективных и субъективных социально-экономических, организационно-рыночных условий.

Принципиально важным является то, что методически формирование предложения основано на имеющихся предпосылках, под которыми понимается предварительное условие, исходный пункт того или иного действия [13].

В свою очередь, условия представляют собой обстоятельства, от которых, чтото зависит [13]. Это означает, что следует выявить набор сложившихся объективных и субъективных обстоятельств, от которых зависит принятие решений о выходе на рынок труда для поиска работы [14].

Чтобы определить набор факторов и условий, которые воздействуют на возникновение предложения на рынке труда следует ориентироваться на характерные особенности лиц, его формирующих.

\section{Baikal Research Journal}

электронный научный журнал Байкальского государственного университета 
Как правило, единицей предложения является конкретное лицо, которое предлагает свой труд (свою рабочую силу) на рынке труда в качестве товара. Данное лицо можно представить, как агента или претендента, который формирует предложение должен осознавать и иметь необходимость предложить свою рабочую силу на рынке. Некоторые ученые вводят понятие «потенциальный работник" [15]. Используя названные методологические подходы, подчеркивается «так потенциальный работник может принять(опровергнуть) предложение занять соответствующую вакансию в зависимости от того, соответствует (или нет) она его представлениям об условиях и уровню оплаты труда [15, с. 104]. То есть, для конкретного индивида (агента или потенциального работника) на рынке труда должны быть созданы предпосылки, которые формируют предпочтения при обосновании принятия решения о продаже своей рабочей силы.

В процессе формирования предложения на рынке труда индивидуальные предпочтения изменяются под воздействием параметров внешней среды с учетом внутренних условий и предпосылок жизнедеятельности индивида. К тому же условия и предпосылки различны по уровням, сегментам и сферам на которых формируется предложение. Условия и предпосылки предполагают изменение предложения под действием целого ряда факторов, которые дифференцируются по разным уровням.

Уровневый аспект формирования предложения связан не только с различной типологией условий и предпосылок, но и с высоким уровнем вероятности достижения разнообразных целей экономического поведения индивида на рынке труда.

Схематично уровень возникновения и готовности к появлению предложения можно представить на рис. 1. В конечном счете, формирование предложения можно представить, как совокупность интегрированных переходов (стадий) от базового, предварительного к исходному уровню принятия решения о необходимости получения работы.

К тому же, процесс формирования предложения состоит из двух этапов. На первом этапе предполагается осознание необходимости выхода на рынок труда или получения новой работы. На втором, осуществляется выбор предпочтений, под действием внешних и внутренних условий. Важно учитывать процессуальные моменты предполагающие, что появление предпосылок является основой формирования условий мотивации, которые корректируются по мере воздействия внешних и внутренних условий, в которых находится субъект формирования предложения на рынке труда.

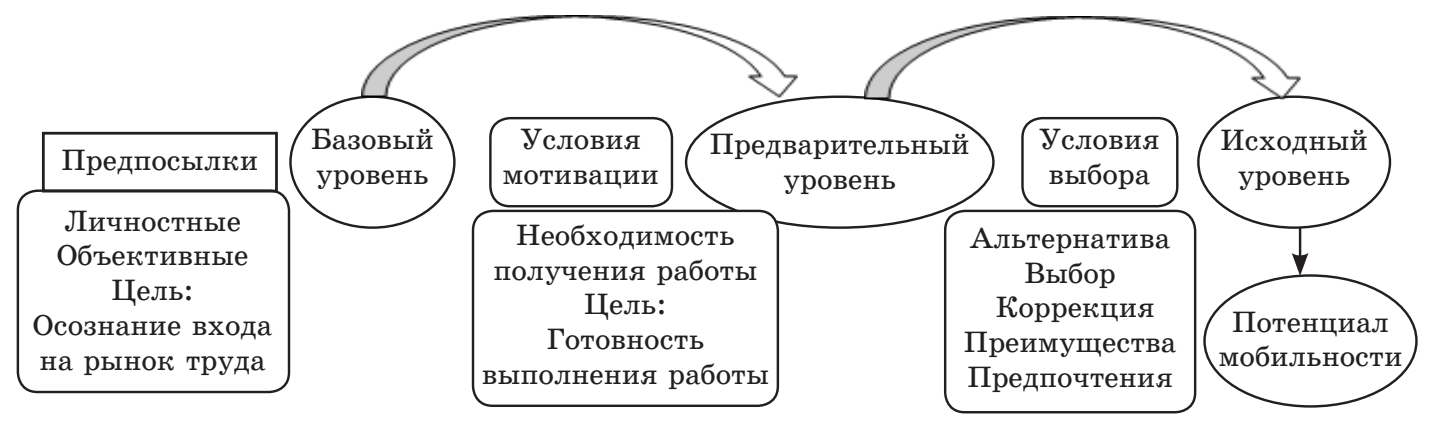

Рис. 1 Этапы возникновения различных уровней предложения

В конечном счете исходный уровень готовности выхода на рынок труда формирует потенциал мобильности. Это связано с тем, что в основе формирования

\section{Baikal Research Journal}


предложения лежит мобильность рабочей силы [16, с. 29]. Действительно, трудовая мобильность связана как с изменением места трудовой деятельности, так и изменением ее существенных характеристик. Как подчеркивают ученые, процесс мобильности рабочей силы с одной стороны обусловлен способностью и готовностью личности к трансформации ее существенных характеристик, а с другой стороны - потребностями отдельных предприятий и экономики в целом в труде определенного содержания и места приложения [16, с. 29].

Таким образом, можно утверждать, что в основе формирования предложения лежит процесс мобильности трудовой мобильности. Ключевым источником является выявление точек, и траекторий, показывающих, когда и в каком направлении происходит формирование готовности человека к смене места работы или необходимости ко входу на рынок труда.

Часто подчеркивается, что у работника есть некоторые опции, связанные с мобильностью. Выбор из многообразных вариантов основан на различных причинах. Решая уйти или остаться на рабочем месте, выходить или не выходить на внешний рынок труда, работник (или потенциальный работник) максимизирует ожидаемую полезность от работы. Данная полезность определяется величиной заработной платы, но не исчерпывается ею и может включать различные не денежные характеристики (содержание работы, наличие профессиональных перспектив, оптимальные взаимоотношения, близость к дому и т.д. [17, с. 218].

Это означает, что предварительно предложение может формироваться как в сфере занятости, когда агент работает, но не доволен условиями оплаты, организации труда, взаимоотношениями в коллективе и т.д. В этом случае причины смены места работы по сути будут определяться предпосылками, формирующими потенциальную текучесть персонала. Причем, условия на новом месте работы должны быть не хуже, а значительно лучше существующих.

Тогда как человек реально ищущий работу часто ориентируется на условия трудовой деятельности, которые могут быть различны, и принятие решения происходит по приоритету предпочтений.

Аналогично формируется предложение для лиц, впервые ищущих работу. В данном случае предпочтения могут иметь траектории не только корректирующего, но и согласующего порядка.

Поэтому, можно утверждать, что предложение на индивидуальном уровне носит мотивационно - корректирующий характер. Можно сформулировать матрицу предпосылок и условий формирования индивидуального предложения на рынке труда (табл.). На этапе формирования базового уровня первостепенное значение имеет воздействие внешней среды, при которой формируется осознание необходимости выхода на рынок. Это может быть обусловлено объективными или субъективными условиями. Предпосылки и условия появления предложения связаны с изменением внешней среды.

К ним могут относится существенными преобразованиями в экономической сфере, кардинальными изменениями на рынке труда. Опыт показывает, что в условиях кризиса на рынок труда выходят не только те, кто был высвобожден из реального сектора экономики, но и увеличивается число лиц, впервые выходящие на рынок труда, а также те, кто имел длительный период отсутствия трудовой деятельности. Поэтому реакция на изменение факторов внешней среды позволяют установить объективные предпосылки формирования предложения труда в определенный период времени. Как правило, знание и учет факторов внешней среды конкретизирует предварительные условия возникновения предложения на труд.

Это означает, что возможности смены места работы или непосредственный выход на рынок труда зависит от состояния социально-экономической среды.

\section{Baikal Research Journal}

электронный научный журнал Байкальского государственного университета 
Если в стабильной экономической ситуации возможности смены места работы обусловлены как правило, стремлением к самореализации и обеспечением перспектив карьерного роста, то в условиях кризисного состояния это возможность избежать высвобождения и безработицы в целом, обеспечение минимальных доходов для существования человека и членов его семьи. Именно факторы внешней среды формируют базовые предпосылки выхода индивида на рынок труда.

Поэтому можно утверждать, что в основе формирования предложения, лежит базовый уровень индивидуальных характеристик лиц, комплектующих предложение, с учетом предпосылок внешней среды (социально-экономической ситуации и конъюнктуры на рынке труда).

Матрица предпосылок и условий формирования предложения на рынке труда

\begin{tabular}{|c|c|c|c|}
\hline \multirow{2}{*}{ Предпосылки } & Базовые & Предварительные & Исходные \\
\hline & \multicolumn{3}{|c|}{ Уровни формирования предложения } \\
\hline \multirow[t]{3}{*}{$\begin{array}{c}\text { Объективные } \\
\text { Внешние }\end{array}$} & $\begin{array}{l}\text { Возможность } \\
\text { Выхода на рынок } \\
\text { труда }\end{array}$ & $\begin{array}{l}\text { Изменение экономиче- } \\
\text { ской ситуации. Динамика } \\
\text { потребительских цен }\end{array}$ & Готовность поиска работы \\
\hline & $\begin{array}{l}\text { Усиление конку- } \\
\text { ренции на рынке } \\
\text { труда }\end{array}$ & $\begin{array}{l}\text { Ситуация на рынке труда } \\
\text { (Изменение конъюнктуры } \\
\text { на рынке труда) }\end{array}$ & $\begin{array}{l}\text { Возможности использова- } \\
\text { ния рыночного механизма } \\
\text { для получения работы }\end{array}$ \\
\hline & $\begin{array}{l}\text { Необходимость } \\
\text { изменений про- } \\
\text { фессионально-ква- } \\
\text { лификационных } \\
\text { характеристик } \\
\end{array}$ & $\begin{array}{l}\text { Возможности изменения } \\
\text { профессионально-квали- } \\
\text { фикационного уровня }\end{array}$ & $\begin{array}{l}\text { Готовность к выполнению } \\
\text { конкретной работы }\end{array}$ \\
\hline \multirow[t]{4}{*}{$\begin{array}{c}\text { Субъективные } \\
\text { Внутренние }\end{array}$} & $\begin{array}{l}\text { Индивидуальная } \\
\text { потребность в } \\
\text { работе }\end{array}$ & $\begin{array}{l}\text { Готовность оценки пре- } \\
\text { имуществ работы перед } \\
\text { досугом }\end{array}$ & $\begin{array}{l}\text { Формирование необходимо- } \\
\text { сти и срочности получения } \\
\text { работы }\end{array}$ \\
\hline & $\begin{array}{l}\text { Мотивационно-кор- } \\
\text { рекционная модель } \\
\text { труда }\end{array}$ & $\begin{array}{l}\text { Формирование мотивов и } \\
\text { приоритетов в работе }\end{array}$ & $\begin{array}{l}\text { Выбор приоритетных } \\
\text { параметров предстоящей } \\
\text { работы }\end{array}$ \\
\hline & $\begin{array}{l}\text { Социальная ответ- } \\
\text { ственность }\end{array}$ & $\begin{array}{l}\text { Осознание необходимо- } \\
\text { сти и срочности входа на } \\
\text { рынок труда }\end{array}$ & $\begin{array}{l}\text { Анализ и коррекция воз- } \\
\text { можных направлений поис- } \\
\text { ка подходящей работы }\end{array}$ \\
\hline & $\begin{array}{l}\text { Жћизненные прин- } \\
\text { ципы ценности и } \\
\text { устремления }\end{array}$ & $\begin{array}{l}\text { Коррекция перспектив } \\
\text { выполнения конкретной } \\
\text { работы }\end{array}$ & $\begin{array}{l}\text { Оценка возможностей и } \\
\text { необходимых компетенций } \\
\text { выполнения конкретной } \\
\text { работы }\end{array}$ \\
\hline
\end{tabular}

Окончательное решение может быть принято с учетом личностных характеристик агента рынка труда. Среди личностных предпосылок базового уровня можно выделить следующие компоненты, которые усиливают или наоборот снижают возможности выхода на рынок труда:

- социальная принадлежность;

- уровень и качество жизни работника;

- профессионально-квалификационный уровень;

- степень мобильности в конкретной профессионально-квалификационной группе.

Именно данные критерии во многом предопределяют развитие и направления траектории поведения индивида на рынке труда относительно не только смены места работы, но и притязаний на занятие рабочих мест. Главной целевой установкой на данном этапе является осознание выхода на рынок труда или принятие решения о смене рабочего места.

\section{Baikal Research Journal}


Совершено иные предпосылки имеют место при формировании предварительного уровня предложения. На данной стадии, особое значение придается условиям и выраженной силой мотивации. Это связано с тем, что если на базовом уровне сформировалось устойчивое осознание потребности в получении работы, то на предварительном уровне важным является сила мотивов поиска и стремления к получению работы.

При этом мотивация устанавливает требования аргументации необходимости принятия решения о возможностях и степени необходимости поиска работы и трудоустройства. Среди поводов возникновения потребности в трудовой деятельности можно зафиксировать следующие:

1) цели получения работы (это могут быть и получение дохода, улучшение условий труда и размеров его оплаты, реализация профессионального, трудового, интеллектуального потенциала и проч.);

2) удовлетворение социально-экономических интересов и потребностей индивида или членов его семьи, предпосылки реализации социальных и личностных планов развития в случае получения места работы;

3) степень срочности и уровень необходимости потребности в трудовой деятельности.

Между тем, желание и аргументы получения работы могут быть реализованы не всегда, поскольку рынок труда предполагает высокой степени вариативность вовлечения в трудовую деятельность.

Предварительные условия образования предложения должны быть обеспечены необходимостью получения работы и возможностями реального осознания входа на рынок труда. Поэтому среди внешних предпосылок предложения актуально фиксировать организационно-рыночные условия, которые сопряжены с выбором и принятием решения о поиске работы в зависимости от степени развития, доступности элементов инфраструктуры рынка труда. Они могут быть обусловлены следующими взаимозависящими условиями.

Во-первых, возможностью использования и доступностью применения коммуникаций инфраструктуры рынка труда для поиска работы и трудоустройства. Как показывает опыт, разветвленная сеть посредников на рынке труда способствует не только увеличению лиц, обратившихся к услугам посредников, но и скорости заполнения вакансий.

Во-вторых, уровнем надежности и оперативности используемой информации о вакансиях.

В-третьих, популярностью, доступностью и умением использования социальных сетей для поиска работы. Использование социальных сетей в настоящее время позволяет содействовать трудоустройству более чем $35 \%$ кандидатов на рынке труда.

Устойчивость предварительного уровня предложения предполагает формирование и фиксацию исходного уровня характеристик индивидуального предложения на рынке труда. Это связано с тем, что в процессе генерирования предложения следует учитывать условия внутреннего обеспечения, которые предполагают не только выбор вариантов, но и корректировка имеющихся и предлагаемых вариантов. На данной стадии существенное значение имеет оценка альтернативного уровня предпочтений предстоящей работы. В основе вариантов выбора могут быть установлены параметры по приоритетам следующих социально-экономическим критериев:

- условия работы (статус, престиж, соцобеспечение);

- уровень заработной платы и условия труда на альтернативных рабочих местах;

- издержки, связанные со сменой работы;

\section{Baikal Research Journal}

электронный научный журнал Байкальского государственного университета 
- временной фактор.

Приоритет предпочтений, с учетом базового уровня личностных характеристик предполагает установление исходных условий предложения.

Исходные предпосылки предложения будут подвержены корректировке под влиянием причин и мотивов стремления в поиске и получении конкретного рабочего места.

Поэтому на этой стадии могут проявляться корректирующие факторы, воздействующие на процесс появления предложения. Они свидетельствуют о способах и элементах высокой степени вариативности получения работы. К такого рода группам ограничений можно отнести:

1. Оценка степени готовности выполнения работы. На сколько индивид готов (физически, профессионально, квалификационно) выполнять потенциальную работу.

2. Самооценка возможностей выполнения работы. Какой перечень требований предъявляется к выполнению конкретной работы, рабочему месту.

3. Уровень притязаний к работе, условиям, режимам труда и отдыха. Насколько выстроены приоритеты к возможной работе. Какие параметры могут корректироваться в ходе поиска работы.

4. Лояльность к фирме-работодателя. Какие критерии могут быть предложены фирмами-работодателями. Какие варианты трудоустройства предлагает работодатель.

Данная группа факторов показывает, каким образом и на основе чего человек, который стремиться получить работу может откорректировать свои действия по поводу найма у нанимателя.

Согласующие условия усиливают или являются препятствием в процессе получения работы и предполагают, что решение о поиске работы должно быть согласовано по следующим параметрам:

1) размер и форма оплаты труда;

2) благоприятные условия труда;

3) предлагаемые режимы труда и отдыха;

4) реальные возможности развития, повышения квалификации.

В этом случае на завершающем этапе можно определиться, какие параметры конкретного рабочего места наиболее предпочтительны для кандидата занять рабочее место. Учет всех вышеперечисленных факторов может определить потенциальный уровень индивидуального предложения на рынке труда (рис. 2).

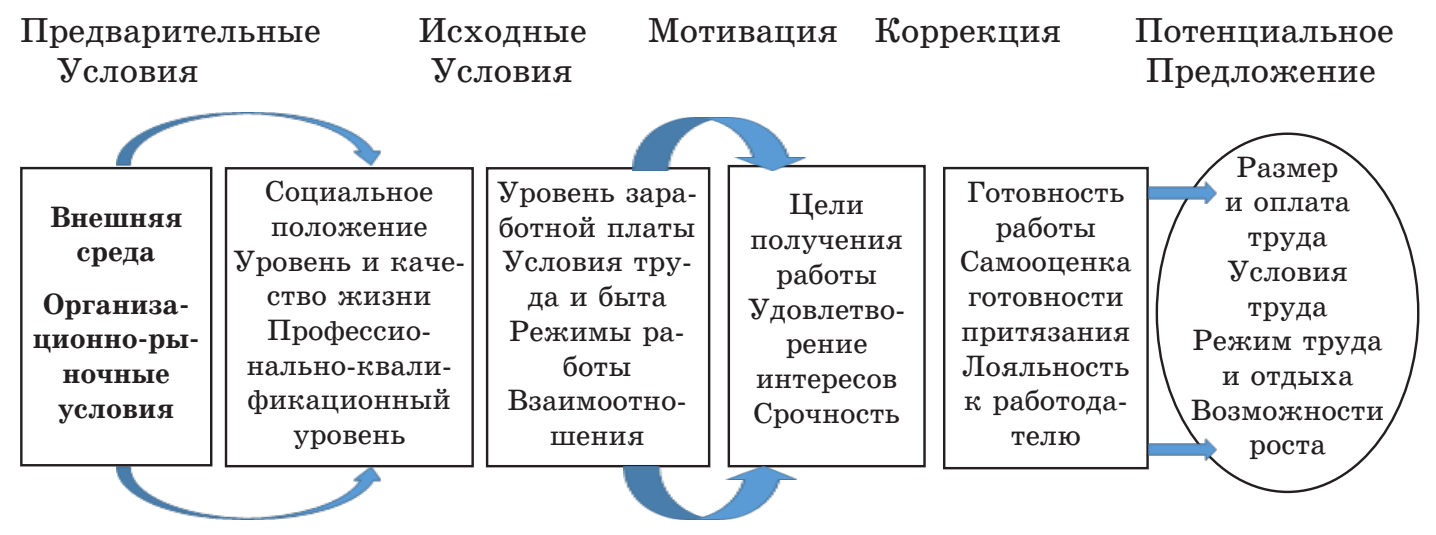

Рис. 2. Процесс форлирования индивидуального предложения

\section{Baikal Research Journal}


Все факторы воздействуют на формирование предложения с различной степенью силой и интенсивностью. Мотивационно-корректирующие (мотивы поиска работы, социально-экономические интересы, установки и потребности в рабочих местах или работы.)

Если на базовом и предварительном уровнях на формирование предложения в большей мере воздействует изменение факторов внешней среды, скорректированные на личностные характеристики носителей рабочей силы, то на исходный уровень влияет степень неудовлетворенности (возмущений) существующей социально-трудовой сферы.

Именно на этом этапе формируется мотивация к целям получения работы, удовлетворении интересов, срочности получения работы. В дальнейшем происходит коррекция и согласование социально-экономических интересов лиц, формирующих предложение на рынке труда.

Таким образом, предлагаемая методология может быть использована для формирования банка оценочных форм для выявления объемов емкости предложения на индивидуальном уровне. Кроме того, данный методологический подход способствует выявлению типологии и определения разновидностей предложения на рынке труда. Использование предлагаемых методических подходов к сущности предложения рабочей силы и позволяет согласовать параметры спроса и предложения на этапе функционирования внутрифирменного рынка труда.

В конечном счете, предлагаемые методические подходы существенно изменяют представление о предложении рабочей силы, природе и сферах ее формирования, что даст возможность осуществлять объективную оценку ситуации на рынке труда.

\section{Список использованной литературы}

1. Рофе А. И. Рынок труда : учебник / А. И. Рофе. - 3-е изд., перераб. и доп. - М. : Кнорус, 2015. - 376 с.

2. Алиев И. М. Экономика труда : учебник / И. М. Алиев, Н. А. Горелов, Л. О. Ильина. - М. : Юрайт, 2013. - 671 с.

3. Рынок труда : учебник / под ред. В. С. Буланова, Н. А. Волгина. - 3-е изд., перераб. и доп. - М. : Экзамен, 2007. - 479 с.

4. Коровкин А. Г. Образовательные характеристики рабочей силы как фактор согласования спроса и предложения на российском рынке труда / А. Г. Коровкин, И. Б. Королев, Е. А. Единак // Научные труды Института народнохозяйственного прогнозирования PAH. - 2015. - № 13. - C. 222-239.

5. Селищев А. С. Микроэкономика / А. С. Селищев. - СПб. : Питер, 2002. - 448 с.

6. Эренберг Р. Дж. Современная экономика труда. Теория и государственная политика / Р. Дж. Эренберг, Р. С. Смит. - М. : Изд-во МГУ, 1996. - 800 с.

7. Вукович Г. Г. Рынок труда : учеб. пособие / Г. Г. Вукович, И. В. Гелета. - Ростов н/Д. : Феникс, 2013. - 238 с.

8. Гимпельсон В. Е. Движение рабочих мест: что говорит российская статистика / В. Е. Гимпельсон, О. Б. Жихарев, Р. И. Капелюшников // Вопросы экономики. - 2014. № 7. - C. 93-126.

9. Баркалов С. А. Индивидуальные стратегии предложения труда: теория и практика / С. А. Баркалов, Д. А. Новиков, С. С. Попов. - М. : Изд-во ИПУ РАН, 2002. - 110 с.

10. Былков В. Г. Закономерные трансформации спроса на рынке труда / В. Г. Былков // Известия Иркутской государственной экономической академии. $-2015 .-$ Т. 25 , № 3. - C. 416-425. - DOI: 10.17150/1993-3541.2015.25(3).416-425.

11. Смирных Л. И. Срочные трудовые договоры: влияние на движение рабочей силы и рабочих мест / Л. И. Смирных // Уровень жизни населения регионов России. - 2014. № 4 . - С. $28-36$.

12. Сырбу А. Н. Домохозяйства как субъекты предложения на рынке труда / А. Н. Сырбу // Транспортное дело России. - 2009. - № 12. - С. 62-63.

\section{Baikal Research Journal}


13. Большая советская энциклопедия : в 30 т. / гл. ред. А. М. Прохоров. - 3-е изд. М. : Сов. энциклопедия, 1969-1978. - 30 т.

14. Гимпельсон В. Е. «Поляризация» или «улучшение»? Эволюция структуры рабочих мест в России в 2000-е годы / В. Е. Гимпельсон, Р. И. Капелюшников // Вопросы экономики. - 2015. - № 7. - С. 87-119.

15. Коровкин А. Г. Проблемы согласования спроса на рабочую силу и ее предложения на российском рынке труда / А. Г. Коровкин // Проблемы прогнозирования. — 2011. № 2. - C. 103-124.

16. Обухова Л. А. Трудовая мобильность как фактор формирования предложения на рынке труда / Л. А. Обухова // Вестник КрасГАУ. - 2006. — № 10. - С. 28-32.

17. Гимпельсон В. Е. Дороги, которые мы вибираем: перемещения на внешнем и внутреннем рынках труда / В. Е. Гимпельсон, Р. И. Капелюшников, А. В. Шарунина // Экономический журнал ВШЭ. - 2016. - Т. 20, № 2. - С. 201-242.

\section{References}

1. Rofe A. I. Rynok truda [Labor market]. $3^{\text {rd }}$ ed. Moscow, Knorus Publ., 2015. 376 p.

2. Aliyev I. M., Gorelov N. A., Ilyina L. O. Ekonomika truda [Labor Economy]. Moscow, Yurait Publ., 2013. $671 \mathrm{p}$.

3. Bulanov V. S., Volgin N. A. (ed.). Rynok truda. [Labor market]. $3^{\text {rd }}$ ed. Moscow, Ekzamen Publ., 2007. 479 p.

4. Korovkin A. G., Korolev I. B., Edinak E. A. Educational characteristics of labor as a factor of supply and demand coordination on the Russian labor market. Nauchnye trudy Instituta narodnokhozyaistvennogo prognozirovaniya $R A N=$ Scientific Works of Institute of Economic Forecasting of the Russian Academy of Sciences, 2015, no. 13, pp. 222-239. (In Russian).

5. Selishchev A. S. Mikroekonomika. [Microeconomics]. Saint Petersburg, Piter Publ., 2002. $448 \mathrm{p}$.

6. Erenberg R. Dzh., Smit R. S. Sovremennaya ekonomika truda. Teoriya i gosudarstvennaya politika. [Modern Labor Economy. Theory and State Policy]. Moscow, M. V. Lomonosov Moscow State University Publ., 1996. 800 p.

7. Vukovitsch G. G., Geleta I. V. Rynok truda. [Labor market]. Rostov-on-Don, Feniks Publ., 2013. 238 p.

8. Gimpelson V. Ye., Zhikharev O. B., Kapelyushnikov R. I. Movement of jobs: what Russian statistics says. Voprosy ekonomiki = Issues of Economy, 2014, no. 7, pp. 93-126. (In Russian).

9. Barkalov S. A., Novikov D. A., Popov S. S. Individual'nye strategii predlozheniya truda: teoriya $i$ praktika. [Individual labor supply strategies: theory and practice]. Moscow, V.A. Trapeznikov Institute of Management Problems Publ., 2002. 110 p.

10. Bylkov V. G. [Regular transformations of demand on the labor market] Izvestiya Irkutskoy gosudarstvennoy ekonomicheskoy akademii = Proceedings of Irkutsk State Academy of Economics, 2015, vol. 25, no. 3, pp. 416-425. DOI: 10.17150/1993-3541.2015.25(3).416-425. (In Russian).

11. Smirnykh L. I. Fixed-term employment contracts: impact on movement of labor and workplaces. Uroven' zhizni naseleniya regionov Rossii = Living Standards of Population in Regions of Russia, 2014, no. 4, pp. 28-36. (In Russian).

12. Syrbu A. N. Households as subjects of supply on the labor market. Transportnoe delo Rossii $=$ Transport business in Russia, 2009, no. 12, pp. 62-63. (In Russian).

13. Prokhorov A. M. (ed.). Bol'shaya sovetskaya entsiklopediya. [Great Soviet Encyclopedia]. $3^{\text {rd }}$ ed. Moscow, Sovetskaya entsiklopediya Publ., 1969-1978.

14. Gimpelson V. Ye., Kapelyushnikov R. I. «Polarization» or «improvement»? Evolution of job structure in Russia in the 2000s. Voprosy ekonomiki = Issues of Economy, 2015, no. 7, pp. 87-119. (In Russian).

15. Korovkin A. G. Problems of demand coordinating of labor and its supply on the Russian labor market. Problemy prognozirovaniya = Problems of Forecasting, 2011, no. 2, pp. 103-124. (In Russian).

\section{Baikal Research Journal}


16. Obukhova L. A. Labor mobility as a factor of supply formation on the labor market. Vestnik Krasnoyarskogo gosudarstvennogo agrarnogo universiteta $=$ Bulletin of Krasnoyarsk State Agrarian University, 2006, no. 10, pp. 28-32. (In Russian).

17. Gimpelson V. Ye., Kapelyushnikov R. I., Sharunina A. V. The roads we choose: movements in external and internal labor markets. Ekonomicheskii zhurnal VShE $=$ The HSE Economic Journal, 2016, vol. 20, no. 2, pp. 201-242. (In Russian).

\section{Информация об авторе}

Былков Владилир Георгиевич - доктор экономических наук, профессор, кафедра экономики труда и управления персоналом, Байкальский государственный университет, 664003, г. Иркутск, ул. Ленина 11, e-mail: bylkovVG@bgu.ru.

\section{Author}

Vladimir G. Bylkov - Doctor habil. in Economics, Professor, Chair of Labor Economy and Personnel Management, Baikal State University, 664003, Irkutsk, 11 Lenin St.; e-mail: bylkovVG@bgu.ru.

\section{Для цитирования}

Былков В. Г. Предложение на рынке труда: методология, природа формирования / В. Г. Былков // Baikal Research Journal. - 2017. - T. 8, № 4. - DOI : 10.17150/2411$\underline{6262.2017 .8(4) .1 .}$

\section{For Citation}

Bylkov V. G. Supply on the labor market: methodology, nature of formation. Baikal Research Journal, 2017, vol. 8, no. 4. DOI: 10.17150/2411-6262.2017.8(4).1.

\section{Baikal Research Journal}

